\title{
Selected diagnostic and therapeutic procedures and the occurrence of vascular access complications in a group of critically ill patients
}

\author{
Anna Michalik', Agnieszka Gniadek², Ewelina Bąk1, Maria Kózka³ \\ ${ }^{1}$ Faculty of Health Sciences, University of Bielsko-Biala, Poland \\ 2 Department of Nursing and Epidemiological Care, Faculty of Health Sciences, Jagiellonian University Collegium \\ Medicum, Cracow, Poland \\ ${ }^{3}$ Department of Clinical Nursing, Institute of Nursing and Midwifery, Faculty of Health Sciences, Jagiellonian University \\ Collegium Medicum, Cracow, Poland
}

\begin{abstract}
Michalik A, Gniadek A, Bąk E, Kózka M. Selected diagnostic and therapeutic procedures and the occurrence of vascular access complications
\end{abstract} in a group of critically ill patients. J Pre-Clin Clin Res. 2018; 12(1): 135-141. doi: 10.26444/jpccr/99726

\begin{abstract}
I Abstract
Introduction. Patients of intensive care units (ICU) require the use of many invasive procedures to maintain the function of inefficient organs. The use of vascular access is an indispensable part of the procedure, but it may involve the risk of lifethreatening complications.

Objective. The aim of the study was to identify selected diagnostic and therapeutic procedures for the occurrence of vascular access complications.

Materials and method. A retrospective study was conducted in a 11-bed multi-profile intensive care unit in the south of Poland. The research used the analysis of individual and collective medical documentation, as well as an original questionnaire to collect the data. Statistical analysis was performed using STATISTICA 10 PL Software.

Results. Among 1,742 vascular accesses inserted, complications occurred in 411 cases. Among complications, the most common occurrence was infection (34\%), cannula occlusion (24.2\%) and accidental removal of the cannula during its use (18.3\%). In relation to the examined patients, in addition to cannulation of venous and arterial vessels, mechanical ventilation, stomach and bladder probing were administered, some patients underwent surgery, had conditions following invasive cardiology procedures or required intra-aortic counter-perfusion.

Conclusions. The multitude of interventions had a significant impact on the occurrence of vascular access complications. The incidence of vascular access complications was influenced by other therapeutic procedures, such as the length of mechanical ventilation, the need to perform tracheotomy, and catheterization of the bladder.
\end{abstract}

\author{
Key words \\ vascular access, risk factors, complications, intensive care
}

\section{INTRODUCTION}

The functioning of intensive care units (ICU) has contributed to the increase in the chances of survival of people in lifethreatening conditions. Contemporary intensive therapy and care could not exist without reliable and permanent endovascular access. In Poland, there is no reliable data on the use of intravascular catheters, whereas in the United States there is data suggesting that the annual use of cannulas in intensive care units amounts to 150 million [1-3]. The procedure for inserting a cannula and its maintenance is associated with the risk of complications that may lead to an increased risk of death. Patients in a life-threatening condition, for the most part require access to large venous vessels, which results from the specificity of the applied diagnostics and therapy. Complications related to central access apply to about $15 \%$ of patients. The most frequent are infectious complications (5-26\%), followed by mechanical complications (5-19\%) and thrombotic complications (2$26 \%$ ) [4]. The occurrence of complications is associated with an extension of hospitalization, an increase in the costs of

Address for correspondence: Ewelina Bak, University of Bielsko-Biala, Faculty of Health Sciences, Bielsko-Biala, Poland, ul. Willowa 2, 43-309 Bielsko- Biała, Poland E-mail: ewelina.bak76@wp.pl

Received: 11 Oktober 2018; accepted: 13 November 2018 conducting therapy, and more importantly - an increase in the morbidity and mortality of patients with a vascular cannula in place $[5,6]$.

Nowadays, much is said about the quality of care provided in health care facilities. Issues concerning the quality of care are included in various types of laws, regulations and ordinances. The quality of care provided results from standards for medical personnel, including minimum personnel qualifications and employment standards, standards for equipment and medical equipment, and standards related to accommodation conditions. Quality is expressed not only as the patient's satisfaction with the services provided, but also as an indicator of adverse events occurring in a given health care facility [7]. Patient safety is a basic measure of quality and is an indispensable element of the care improvement system [8]. Patients undergoing intensive therapy and care require a special approach in relation to the risk of various complications related to diagnosis and therapy. Vascular access is an indispensable element of the procedure, but it may be associated with the occurrence of adverse events. Understanding the factors that correlate with the occurrence of complications among patients treated in the intensive care unit may improve their safety. 


\section{OBJECTIVE}

The aim of the study was to evaluate the influence of selected diagnostic and therapeutic procedures applied in the group of critically ill patients on the occurrence of vascular access complications.

\section{MATERIALS AND METHOD}

The research was carried out from January 2013 - March 2015 in the 11-bed multi-profile Anaesthesiology and Intensive Care Unit (the ICU) of a Municipal Hospital in the south of Poland. The study included people qualified for treatment in the ICU in the period from 1 January 2012 - 30 June 2013 , in whom the procedure of inserting central and/or peripheral vascular access was performed (597 patients). The study excluded patients who remained in the ICU during the study period, but were admitted before 1 January 2012 (6 patients) and patients who were admitted with vascular access (17 persons).

The research involved retrospective analysis using the analysis of individual and collective medical documentation, which included: history of the disease, individual care card, intensive treatment card, medical and nursing reports, book of procedures, diagnostic and microbiological results, and nursing staff work schedule. The SOFA and APACHE II classifying scales were used in the study, and the TISS-28 scale was used to assess therapeutic effort $[9,10]$.

Additionally, the research used an original questionnaire to obtain demographic data of the surveyed group of patients, the date of admission to the hospital, the date of admission to the ICU, date of discharge / death, admission mode, and type of admission (primary / secondary). The number and type of vascular cannulas inserted, the duration of maintenance, number of manipulations and the reason for decanulation were also monitored.

During the collection of research material, the applicable procedures and standards of conduct, as well as medical equipment used for cannulation of vessels, did not change. Permission of the Bioethics Committee and the Hospital Directorate was obtained to conduct the study.

Statistical analysis was performed using STATISTICA 10 PL Software. In the homogeneity analysis of the examined groups with respect to independent variables, the one-way analysis of variance (ANOVA) was used. In the case of nonhomogeneous variance, the Mann-Whitney U test was used. The influence of many independent variables on the dependent variable was analyzed using multiple backward regression analysis. Evaluation of interdependence of qualitative or quantitative traits of the ordinal scale type was made using Pearson chi square $(\chi 2)$ independence tests or chi-square independence tests $(\chi 2)$ using the highest credibility function (NW). The study also used the odds ratio and relative risk to determine the ratio of the likelihood of complications of endovascular access. Statistical inference was carried out at the significance level of $\alpha=0.05$.

\section{RESULTS}

Almost all the patients were admitted to the hospital in an emergency mode (96.5\%). For more than half of the patients
(52.8\%), the stay at the ICU was their primary stay. Among the indications for admission to the ward were acute respiratory failure (51.6\%), condition following sudden cardiac arrest (17.4\%), septic shock (16.1\%), decompensation of chronic heart failure (5.5\%), decompensation of chronic respiratory failure (4.9\%), hypovolaemic shock (3.5\%), polytrauma $(0.8 \%)$ and Guillain-Barre syndrome (0.2\%). The main reason for hospitalization in both men and women was acute respiratory failure. Analyzing the reason for the admission of the patients depending on the diagnosis and gender, no statistically significant differences were found $(\chi 2=4.46, \mathrm{df}=7 ; \mathrm{p}=0.7261)$.

More than $5 \%$ of the patients (5.9\%) were admitted to the ICU with positive blood cultures. Among the cultured microorganisms were: Gram positive bacteria, i.e. Methicillinresistant and -sensitiveStaphylococcus aureus and Gram negative: Klebsiella oxytoca, Escherichia coli, Klebsiella pneumoniae ESBL (+), Prevotella sp., Porphyromonas sp., Acinetobacter baumanii.

Almost one-third of the respondents (30.6\%) had surgery before admission to ICU, mainly in the abdominal and skull cavities.

The age of the respondents ranged from $13-96$ years (average 67 years, $S D=16.08$ ). Men accounted for $60 \%$ of hospitalized patients. Statistical analysis between gender in particular age groups showed the difference at the statistical significance level $(\mathrm{p}=0.0003)$.

The average length of stay of patients in the ward was 6.08 $(\mathrm{SD}=6.25)$ days; time of hospitalization $-16.87(\mathrm{SD}=15.72)$ days.

When assessing the patient's condition using the classification scales, the patients were found to have an average of $8.19(\mathrm{SD}=3.44)$ SOFA, with a minimum threshold of one and a maximum of 20, whereas on the APACHE II scale they were rated $27.26(\mathrm{SD}=9.67)$ points, on average, with a minimum threshold of 6 and a maximum of 63 . Further analysis concerned the influence of the severity of the patients' disease on the basis of the obtained number of SOFA and APACHE II points for the occurrence of complications related to the implantation of the vascular catheter. It was shown that the average number of points in the SOFA scale in the group of patients with complications of $8.33(\mathrm{SD}=3.48)$, and in the group of patients without complications 8.09 $(\mathrm{SD}=3.41)$. There was no statistically significant difference in the incidence of complications depending on the degree of organ failure assessed on the SOFA scale $(p=0.5107)$. When assessing the severity of patients on the APACHE II scale, the average number of points in the group of patients without complications was $27.98(\mathrm{SD}=10.11)$, and in the group of persons with complications - $26.23(\mathrm{SD}=8.87)$. Also in this case, there was no statistically significant difference between the incidence of complications depending on the severity of the disease examined with this scale $(\mathrm{p}=0.1004)$.

The hospitalized patients during their stay in the ICU on the TISS-28 scale obtained on average 233.55 points $(\mathrm{SD}=232.61)$, in the range from $13-1,913$ points. The average number of points on the TISS-28 scale within one day of the patient's stay in the ward (TISS-28 average) was 32.58 $(\mathrm{SD}=7.50)$. In the group of patients with endovascular access complications, the average number of points on the TISS28 scale was $349.26(\mathrm{SD}=308.84)$, ranging from $13-1,913$ points. In the group of patients without complications, on the other hand, the average number of points was 162.23 $(\mathrm{SD}=123.12)$, in the range from $18-628$ points. It was shown 
that significantly more often the multitude of interventions undertaken according to the TISS- 28 scale influenced the occurrence of complications $(\mathrm{p}<0.0001)$. Taking into account the average daily number of points obtained by the patients hospitalized in the ICU, there was no statistically significant difference $(p=0.5190)$. Patients with TISS-28 scale complications achieved an average of 32.34 points $(\mathrm{SD}=6.74)$, in the range of $4.33-66$, while patients who did not develop complications received 32.75 points $(\mathrm{SD}=7)$., 93$)$, in the range from $2-60.50$ points.

The impact of the workload of medical personnel on the occurrence of complications was obtained by calculating the average number of patients under the care of one nurse (nurse-patient index) during the whole patient's stay in the ward, for each patient separately. The number of patients per nurse during on-call time ranged from $0.5-2.5$, on average $1.63(\mathrm{SD}=0.40)$. In the group of patients with complications, the nurse-patient index was $1.64(\mathrm{SD}=0.39)$, and in the group of patients without complications, the index was lower $1.62(\mathrm{SD}=0.40)$. Statistical analysis showed no significant difference between the average number of nursing personnel per patient with complications and with no complications $(\mathrm{p}=0.4664)$.

The intensity of the central vascular line in the study period among all patients was $82.4 \%$, and the intensity of the peripheral vascular line was $97.3 \%$. The number of implanted vascular cannulae varied depending on the patient and type of intravascular access and ranged from $1-11$. Among 1,742 vascular accesses inserted, complications occurred in 411 cases. Among complications, the most common occurrence was infection (34\%), cannula occlusion (24.2\%) and accidental removal of the cannula during its use (18.3\%).

To assess the impact of various intensive care and care methods provided to the ICU patients on vascular access complications, it was examined whether such procedures as surgery, mechanical ventilation, number of days of using replacement ventilation, stomach and bladder probing, tracheotomy, coronary angiography and intraaortic counter-flow, have influence on the occurrence of vascular complications. It was also examined whether the cause of admission to the intensive care unit, primary blood infection at admission, secondary stay in the ward, was related to the incidence of vascular access complications. Analysis showed that secondary stay in the ward, blood on the day of admission (BSI), surgery, coronary angiography, the presence of the balloon for intra-aortic balloon inflation and the nasogastric tube, did not have any relation to the occurrence of complications $(\mathrm{p}>0.05)$. The reason for admitting the patient to the ICU and the presence of such variables as mechanical ventilation time, the need to perform tracheotomy, and the insertion of a catheter into the urinary bladder, had a significant effect on the occurrence of complications $(\mathrm{p}<0.05)$.

Most often, vascular access complications occurred among patients hospitalized for decompensation of chronic respiratory failure $(72.4 \%, \mathrm{OR}=4.55, \mathrm{RR}=1.98)$, followed by the group with septic shock $(40.6 \%, \mathrm{OR}=1 ; 12, \mathrm{RR}=1.07)$, polytrauma $(40.0 \%, \mathrm{OR}=1.07 ; \mathrm{RR}=1.04)$. No complications occurred in patients admitted to have plasmapheresis performed in the course of Guillain-Barre syndrome $(\chi 2=17.03 ; \mathrm{p}=0.0172)$ (Fig. 1).

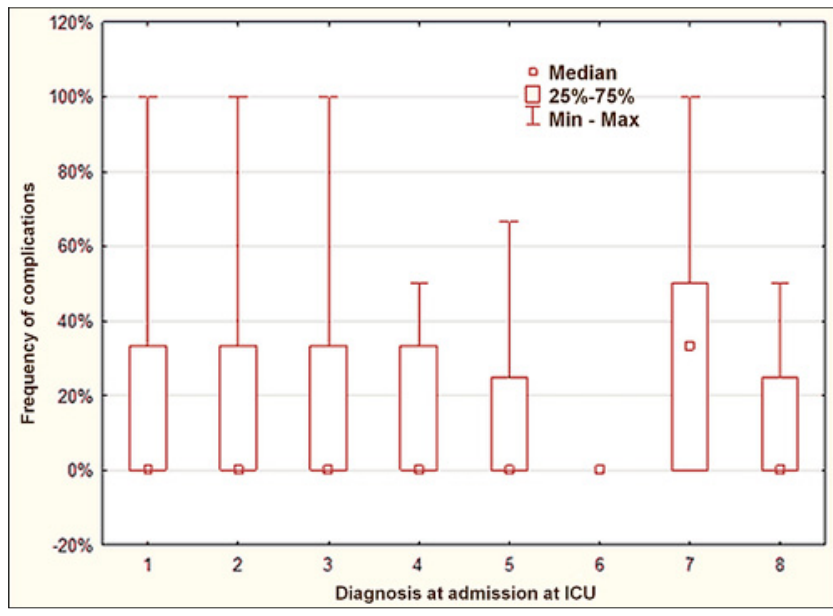

Figure 1. Frequency of complications of vascular access depending on diagnosis 1 - condition following sudden cardiac arrest, 2 - acute respiratory failure, 3 septic shock, 4 - politrauma, 5- decompensation of heart failure, 6-Guillain-Barre syndrome, 7 - decompensation of chronic respiratory failure, 8 - hypovolaemic shock

Of the 597 patients hospitalized in the ward during the study period, 557 (93.5\%) were treated using a ventilator, of which 526 patients $(94.4 \%)$ had invasive ventilation. The duration of replacement ventilation was 5.159 days, on average $(\mathrm{SD}=5.03)$. Analysis showed that mechanical ventilation did not affect the incidence of vascular access complications $(p=0.6684)$. The number of days of ventilatory therapy, however, had an impact on the incidence of complications. With the extension of the duration of mechanical ventilation, the incidence of vascular access complications increased significantly $(\mathrm{p}<0.0001)$ (Fig. 2).

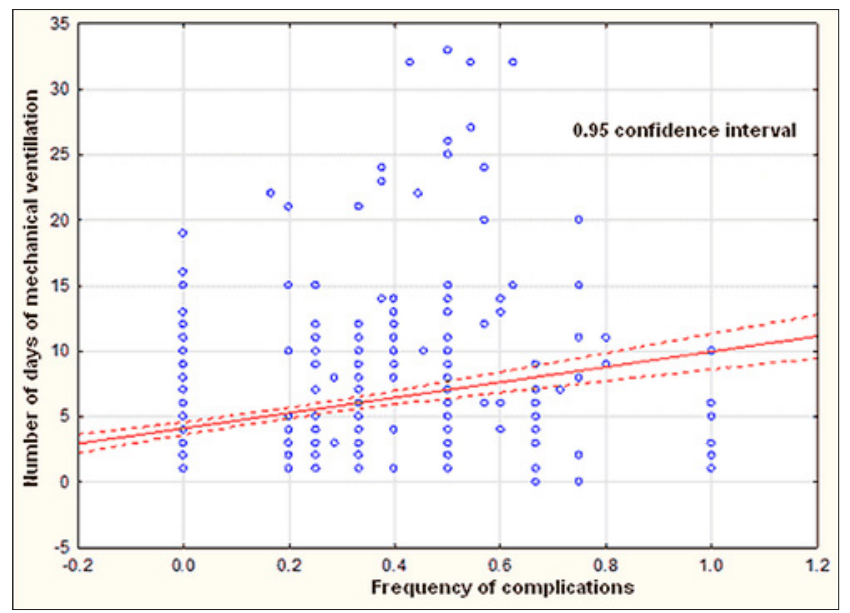

Figure 2. Frequency of complications of vascular accesses and number of days of mechanical ventilation

The tracheotomy procedure was performed in 86 patients staying in the ICU, of whom 58 (67.4\%) had vascular access complications. In the group of patients in whom the procedure for selecting tracheostomy was not performed, the percentage of complications of vascular cannulation was lower and amounted to only $33.4 \%$. Analysis showed a statistically significant difference in the incidence of vascular access complications in the group of patients with tracheostomy and without tracheostomy $(\mathrm{p}<0.0001)$ (Fig. 3). 


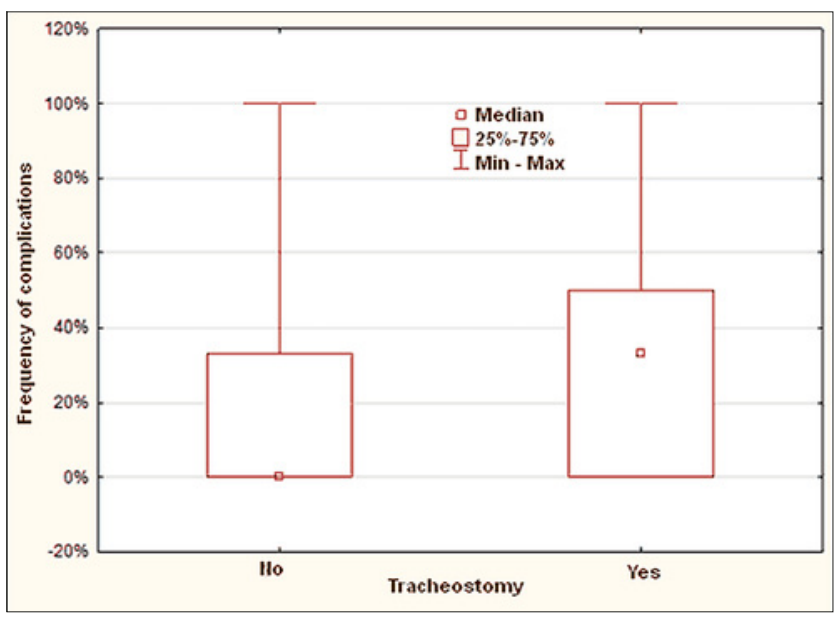

Figure 3. Percentage of vascular access complications and tracheostomy

The odds ratio (OR) and the relative risk (RR) with a confidence interval $(95 \% \mathrm{CI})$ were also examined for these variables, which were $\mathrm{OR}=4.13(95 \%, \mathrm{CI} 2.54-6.72)$ and $\mathrm{RR}=2$, respectively, 2.02 (95\% CI $1.24-3.29)$, which means that complications of endovascular accesses were twice as likely in the group of patients with tracheostomy as in patients without tracheostomy.

In the examined group, in 580 patients treated in the ICU, bladder catheterization procedure was performed, of whom 226 patients (39.0\%) with a Foley catheter developed for vascular access complications. In the group of patients without bladder catheterization (17 patients - 2.84\%) complications of vascular cannulation occurred in two cases (11.8\%). Analysis of the occurrence of vascular access complications in the group of patients subjected to bladder catheterization procedure, and patients without the need for the Foley catheter, showed a statistically significant difference $(\mathrm{p}=0.0261)$ (Fig. 4).

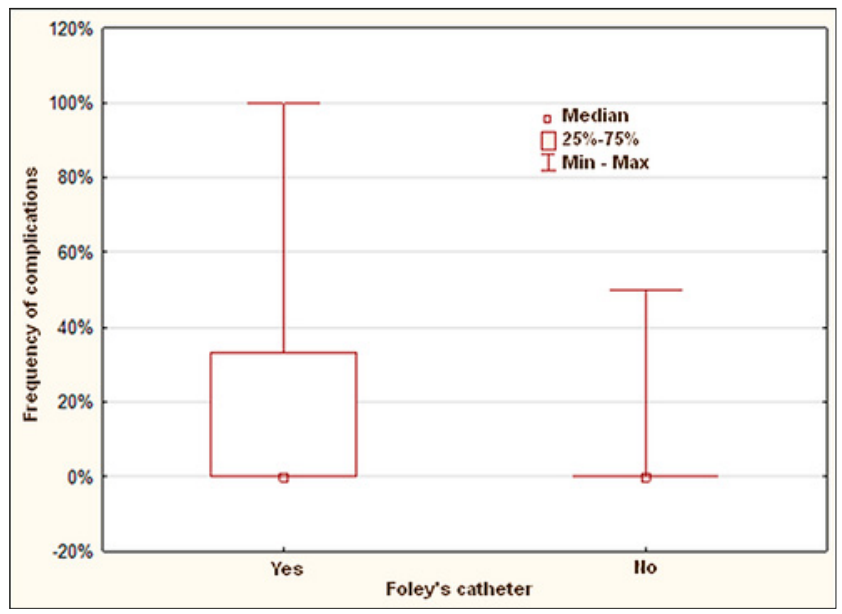

Figure 4. Incidence of vascular access complications depending on bladder catheterization

The occurrence of complications related to cannulation of vessels was almost five times more likely in the group of patients with the Foley catheter $(\mathrm{RR}=4.82$ (95\% CI 1.09 21.26) $\mathrm{OR}=3.32$ (95\% CI $0.75-14.67)$.

Based on the collected data, a question was posed, namely, which of the independent variables significantly influenced the occurrence of vascular access complications.
By eliminating the least significant independent variables in the subsequent steps of regression analysis, the only statistically significant factors influencing the occurrence of vascular access complications in the study group were decompensation of chronic respiratory failure, duration of intensive care unit stay, time of hospitalization, and the average number of TISS-28 interventions, for which the coefficient of determination was $\mathrm{R}^{2}=0.18$, with a significance level of $\mathrm{p}<0.001$. The demonstrated correlation was positive with decompensation of chronic respiratory failure, duration of stay in the intensive care unit and time of hospitalization, and negative with the average number of interventions undertaken at the TISS-28 scale (Tab. 1).

Table 1. Risk factors for vascular access complications considering level of significance

\begin{tabular}{lccccc}
\hline Variable & $\mathrm{b}$ & $\begin{array}{c}\text { Standard } \\
\text { error } \\
\text { with b }\end{array}$ & $\mathrm{b}^{*}$ & \multicolumn{3}{c}{$\begin{array}{c}\text { Standard } \\
\text { error } \\
\text { with b }\end{array}$} & $\mathrm{p}$ \\
\hline Free word & 0.114 & 0.039 & 0.133 & 0.045 & 0.0036 \\
\hline $\begin{array}{l}\text { Decompensation of chronic } \\
\text { respiratory failure }\end{array}$ & 0.298 & 0.043 & 0.012 & 0.002 & $<0.0001$ \\
\hline Time of stay at ICU & 0.146 & 0.043 & 0.002 & 0.001 & 0.0008 \\
\hline Time of hospitalization & -0.107 & 0.039 & -0.004 & 0.001 & 0.0070 \\
\hline TISS-28 average & & & & 0.048 & 0.0003 \\
\hline
\end{tabular}

$B$ - variable regression coefficient; $b$ * - directional coefficient; $p$ - significance level

\section{DISCUSSION}

The specificity of intensive care units is the use of specialized diagnostic and therapeutic techniques, consisting of invasive monitoring and mechanical support of the function of inefficient organs or systems. Patients treated in intensive care units are often subjected to multiple invasive procedures simultaneously. In addition to the cannulation of venous and arterial vessels, mechanical ventilation, stomach and bladder probing were administered, and some patients underwent surgery, had conditions following invasive cardiology procedures or required intraaortic counterperfusion. Each of the listed procedures in itself poses a risk of complications, including infectious complications. A prospective clinical-epidemiological analysis conducted among the patients hospitalized in the Anaesthesiology and Intensive Care Ward in Szczecin, northwest Poland, showed that the risk factors associated with diagnostics and treatment were significantly influenced the procedures of the bronchial tree toilet ( $\mathrm{p}<0.0002)$, tracheostomy ( $\mathrm{p}$ $<0.0001)$, body cavity drainage $(\mathrm{p}<0.0001)$, tube feeding ( $\mathrm{p}$ $<0.008)$, central vessel cannulation $(\mathrm{p}<0.0001)$ and parenteral nutrition. Male gender, surplus weight and obesity were significant infection factors associated with the patient in the studies by Wieder-Huszla et al. [11, 12]. Similarly, studies conducted by Kołpa et al. indicated that the invasiveness of the procedures applied is an important risk factor for the occurrence of hospital infection in the group of critically ill patients [13]. Own research has shown that such independent variables as the time of mechanical ventilation, the need for tracheotomy and the presence of a catheter in the urinary bladder correlated with the occurrence of complications related to endovascular access. 
There are few publications on the impact of tracheotomy on the incidence of infectious complications associated with vascular access. Research by Garnacho-Montero et al. [14] and Lorente et al. $[15,16]$ among patients with central vascular access, divided into persons who underwent the procedure for selecting tracheostomy and patients without artificial respiratory tract, showed a greater percentage of catheter colonization in the group of people with tracheostomy. Analysis of own research confirms the reports of other authors, as it showed that the occurrence of complications of endovascular access was twice as likely in the group of patients with tracheostomy, in comparison with the group of patients without tracheostomy.

With regard to patients requiring the Foley catheter, it was shown that urinary catheterization was associated with a nearly five-fold higher risk of vascular access complications.

Analysis of own studies did not confirm the hypothesis that the severity of the patient's condition assessed with the classification scales SOFA and APACHE II influenced the occurrence of complications. The highest percentage of complications occurred in the range of $6-10$ points and $11-24$ points on the SOFA scale $(41.6 \%$ and $41.3 \%$, respectively), whereas on the APACHE II scale it was noted that with the increase in the number of points to 29, the percentage of complications increased, then in the group of patients with more than 30 points it reached the lowest value (33.1\%). The situation can be explained by the fact of increased mortality in this group of patients and the short period of cannula maintenance in situ due to the initially critical condition of the patient. However, own research concerned the assessment of the severity of the patient's condition in general on the occurrence of complications, without differentiating between mechanical or infectious complications. It is difficult to compare the reports of other authors in this area, because they had different end points than this study. Studies conducted by van der Kooi et al., however, revealed no statistically significant effect of the increased number of APACHE II points on the occurrence of catheter infection [17].

Work in ICUs requires the cooperation in an interdisciplinary team, as the care of the patient in a critical condition is associated with undertaking and performing many specialist services that require both extensive theoretical knowledge and high manual efficiency. ICU patients are a group of people with a high risk of complications and a high percentage of deaths. Therefore, safety in patient care is of the highest importance and it can only be provided by professional medical staff in all respects. Following the guidelines is conducive to improving the quality of care provided. Proper nursing staff, understood as the number of nursing staff in relation to the number of patients and appropriate post-graduate qualifications of nurses, guarantee the provision of good quality care [18-20]. The quality of care depends on the multifaceted compliance with procedures, and the selective application of rules of conduct reduces the quality of care over vascular access.

The workload of nursing staff is a widely discussed issue due to its implications related to the quality of care [21, 22]. Nurses' work is understood as the time a nursing team spends in providing direct or indirect care to a patient. These activities vary depending on the degree of the patient's independence, the complexity of the underlying disease, profile of the ward, or the qualifications of the team members who care for the patient. The high quality, safe and direct care that reflects the needs reported by the patient should be the goal of the therapeutic team members [23]. The work of a nurse in ICU is considered very burdensome, which is connected not only with the fact of continuous and direct observation of the patient's condition, quick and purposeful response to changes in the state of health, speed in decision making, but also with the specificity and working conditions [24]. The workload of nurses is important for taking care of critically ill patients. Excessive workload, caused by an insufficient number of nurses dealing with life-threatening patients, can be a source of many complications contributing to unfavourable results of treatment and nursing.

In Poland, only the TISS-28 scale is used to assess nursing staff, which is mainly used to calculate the costs of treating patients in ICUs [25]. American research, already begun in the 1980s, showed a relationship between staff shortages and work overload of nurses, which was manifested not only in increased absenteeism from work, increased rotation, but more importantly - poorer treatment results [26-28]. Conclusions from the RN4CAST study (Registered Nurse Forecasting: Human Resources Planning in Nursing), the aim of which was to formulate universal and modern assumptions for the policy of effective employment and management of nursing staff, and to demonstrate how the number and qualifications of nursing staff shape the results of treatment and the quality of patient care, and the internal diseases and surgical wards performed among nurses, have shown that a lower number of nurses affects mortality and increases the costs of treatment related to the occurrence of complications, and the appropriate staff is the basis for the quality of care $[29,30]$. The results of research conducted in ICUs show that factors such as: length of stay in the ward, mortality, severity of the condition, age, surgical interventions correlate with the workload of nursing staff [31].

Based on data developed for the Wielkopolskie and Kujawsko-Pomorskie provinces in Poland, the average number of patients under the care of one nurse was estimated. The number of patients per nurse in ICU was less than one about $0.7-0.9$ patient per nurse [32]. Own research showed that the average nurse-patient ratio was 1.6 which, however, did not significantly affect the occurrence of complications in the examined group of patients, because in the group of patients with complications this index was 1.64 , and in the group without complications -1.62 . The calculated nursepatient index, however, is an estimated parameter, not including all activities related to the provision of services in the course of the nursing service. This is due to the fact that it is difficult to estimate the time spent on participating in resuscitation activities in the hospital area, assisting in the establishment of central vascular access in patients outside the ICU, or performing cardioversion in other hospital wards. The nursing staff provides direct and continuous care over the critically ill and performs various procedures that may expose the patient to the occurrence of infectious complications [33]. Variables such as: nurse-patient ratio and increased staff turnover can affect the safety of patients under care. In addition, an inadequate number of nursing staff was associated with an increased risk of iatrogenic and adverse events [34-39]. A review of literature performed by Stone et al. showed a significant association between nursing staff and the occurrence of nosocomial infections [33]. What is more, critically ill patients, due to the use of 
many invasive methods of maintaining vital functions, are exposed to infectious complications related to the artificial respiratory tract, catheterization of the urinary bladder and cannulation of venous and arterial vessels. Thus, many researchers also see the connection between the number of nurses employed and the occurrence of CLA-BSI [40,41]. The lack of permanent staff and associated rotation also correlates with the increased risk of nosocomial infections, as demonstrated in a study conducted in eight intensive care units over a two-year period. The researchers found that the risk of CLA-BSI was 2.6 times higher in patients who were nursed over $60 \%$ of the time by nurses who were not employed on a permanent basis [41]. This is consistent with the reports by Pronovost et al. [42].

The research conducted draws attention to the risk factors of vascular access complications in a group of critically ill patients treated at ICU. It seems reasonable that these studies should be continued with the division into individual vascular access and distinguishing specific critical points for specific intravascular cannulae with a breakdown into mechanical and infectious complications.

The results of own research are difficult to compare with those of other authors, which results from other endpoints adopted in individual literature reports. The occurrence of complications is associated with several risk factors related to the patient's state of health, organizational conditions, human resources, the type of cannula and the procedure following its implantation. In order to prevent complications, a holistic approach to the patient and responsibility in performing diagnostic and therapeutic procedures and the cooperation of all members of the therapeutic team in the care of vascular access with respect to the observance of guidelines and recommendations, as well as the necessity to conduct scientific research, are necessary.

The results of the presented single-centre study are one of the few available in Poland. However, they are of limited character because single-centre observational studies cannot be treated as a reference point for the entire population of Polish patients treated in ICUs. The data obtained, however, led to further actions aimed at increasing the level of care for patients with vascular catheters in order to minimize the number of complications. It is advisable to update the implemented procedures and shape correct behaviours among the medical and nursing staff in the care of a critically ill patient with assumed vascular access.

\section{CONCLUSIONS}

1. The use of peripheral venous vascular access was characterized by a significantly higher incidence of complications compared to other endovascular access used in patients hospitalized in ICU.

2. The multitude of interventions undertaken during the overall time of vascular access to the patient had a significant influence on the occurrence of vascular access complications assessed with the TISS-28 scale, not the average daily number of interventions performed during maintenance of the intravascular cannula.

3. The incidence of vascular access complications was influenced by other therapeutic procedures, such as the length of mechanical ventilation, the need to perform tracheotomy and catheterization of the bladder.
4. The severity of patients' health status, assessed with the SOFA and APACHE II scales, did not affect the frequency of complications associated with the use of vascular access. 5. Statistically significant risk factors having a positive effect on the occurrence of vascular access complications in the studied group were decompensation of chronic respiratory failure, hospitalization and stay in the Anesthesiology and Intensive Care Ward, while the negative number of TISS28 interventions had a negative significant impact on the occurrence of complications.

\section{Author contributions conflict of interest}

All authors contributed equally to the preparation of the manuscript and declare that they have no conflicting interests.

This research did not receive any specific grant from funding agencies in the public, commercial, or not-for-profit sectors.

\section{REFERENCES}

1. Mermel LA, Farr BM, Sherertz RJ, Raad II, O'Grady N, Harris JS, Craven DE. Guidelines for the management of intravascular catheter-related infections. Clin Infect Dis 2001; 32(9): 1249-1272.

2. Deduńska K, Dyk D. Prevention of bloodstream infections associated with the maintenance of central vascular catheters - literature review. Anest Ratow 2015; 9: 420-426.

3. Collignon PJ. Intravascular catheter associated sepsis: a common problem. The Australian Study on Intravascular Catheter Associated Sepsis. Med J Aust 1994; 161(6): 374-378.

4. Webster J, Clarke S, Paterson D, Hutton A, van Dyk S, Gale C, Hopkins T. Routine care of peripheral intravenous catheters versus clinically indicated replacement: randomised controlled trial. BMJ 2008; 337: a399.

5.Lim MY, Al-Kali A, Ashrani AA, Begna KH, Elliott MA, Hogan WJ, Hook CC, Kaufmann SH, Letendre L, Litzow MR, Patnaik MS, Pardanani A, Tefferi A, Wolanskyj AP, Grill DE, Pruthi RK. Comparison of complication rates of Hickman catheters versus peripherally inserted central catheters in patients with acute myeloid leukemia undergoing induction chemotherapy. Leuk Lymphoma 2013; 54(6): 1263-1267.

6. Napalkov P, Felici DM, Chu LK, Jacobs Jr, Begelman SM. Incidence of catheter-related complications in patients with central venous or hemodialysis catheters: a health care claims database analysis. BMC Cardiovasc Disord 2013; 13: 86.

7. Bembnowska M., Jośko-Ochojska J. Quality Management in Healthcare. Hyg Publ Health 2015; 50(3): 457-462.

8. Cranovsky R., Krajewski R. Adverse Events in Treatment - The Scale of the Problem Med Prakt 2011; 2: 127-132.

9. Bouch C., Thompson JP. Severity scoring system in the critically ill. Continuing Education in Anaesthesia, Critical Care \& Pain 2008; $8(5): 181-185$.

10. Miranda DR. The Therapeutic Intervention Scoring System: one single tool for the evaluation of workload the work process and management? Intensive Care Med 1997; 23(6): 615-617.

11. Wieder-Huszla S. Monitoring of nosocomial infections in intensive care unit. Ann Acad Med Stetin 2010; 56(3): 20-29.

12. Wieder-Huszla S, Jurczak A, Grochans E, Giedrys-Kalemba S. Occurrence of Infections Among Patients After Surgical Procedures Staying in the Intensive Care Unit. Probl Hig Epidemiol 2012; 93(3): 586-592.

13. Kołpa M, Wałaszek M, Gniadek A, Wolak Z, Dobroś W. Incidence, Microbiological Profile and Risk Factors of Healthcare-Associated Infections in Intensive Care Units: A 10 Year Observation in a Provincial Hospital in Southern Poland. Int J Environ Res Public. Health. 2018; 15(1): 112 doi: 10.3390/ijerph15010112.

14. Garnacho-Montero J, Aldabo-Pallas T, Palomar-Martinez M, Vallés J, Almirante B, Garcés R, Grill F, Pujol M, Arenas-Giménez C, Mesalles E, Escoresca-Ortega A, de Cueto M, Ortiz-Leyba C. Risk factors and prognosis of catheter-related bloodstream infection in critically ill patients: a multicenter study. Intensive Care Med 2008; 34(12): 2185-2193.

15. Lorente L. Prevention of catheter-related infection: which catheter, which access and which insertion technique should be chosen? Reanimation 2013; 22: S409-416. 
16. Lorente L, Jimenez A, Naranjo C, Martinez J, Iribarren JL, Jimenez JJ, Santacreu R, Martin MM, Mora ML. Higher incidence of catheterrelated bacteremia in jugular site with tracheostomy than in femoral site. Infect Control Hosp Epidemiol 2010; 31(3): 311-313.

17.van der Kooi T, Wille JC, van Benthem BH. Catheter application, insertion vein and length of ICU stay prior to insertion affect the risk of catheter-related bloodstream infection. J Hosp Infect 2012; 80(3): 238-244.

18. Ambrose C. Recruitment problem in intensive care: a solution. Nurs Stand 2002; 17(12): 39-40.

19. Abualrub RF. Nursing shortage in Jordan: what is the solution? J Prof Nurs 2007; 23(2): 117-120.

20. Volpatti C, Leathley M, Walley KR, Dodek PM. Time-weighted nursing demand is a better predictor than midnight census of nursing supply in an intensive care unit. J Crit Care 2000; 15(4): 147-150.

21. Lenartowicz H. Quality Management in Nursing. Warszawa, Centrum Edukacji Medycznej 1998.

22. Kózka M. Efficiency of Vocational Education in First Degree Nursing Studies During the Transformation of the Educational System. Uniwersyteckie Wydawnictwo Medyczne Vesalius, Kraków 2008.

23. Pires Siqueira EM, Davies Ribeiro M, Silva Souza RC, de Souza Machado F, Diccini S. Correlation between work load of nursing and severity of critical general, neurological and cardiac patients. Esc Anna Nery 2015; 19: 233-238.

24. Głowacka M, Orzoł A, Soleta A. Workload in the Practice of Nurses at Anaesthesiology and Intensive Care Wards. J Public Health Nurs Med Rescue 2012; 4: 5-13.

25. Miranda DR, de Rijk A, Schaufeli W. Simplified Therapeutic Intervention Scoring System: the TISS-28 items-results from a multicenter study. Crit Care Med 1996; 24(1): 64-73.

26. Aiken LJ, Clarke SP, Sloane DM, Sochalski J, Silber JH. Hospital nurse staffing and patient mortality, nurse burnout, and job dissatisfaction. JAMA 2002; 288(16): 1987-1993.

27. Darvas JA., Hawkins LG. What makes a good intensive care unit: a nursing perspective. Aust Crit Care 2002; 15(2): 77-82.

28. Cavanagh SJ. Job satisfaction of nursing staff working in hospitals. J Adv Nurs 1992; 17: 704-711.

29. Aiken L, Sloane D, Bruynee L, Van den Heede K, Griffiths P, Busse R, Diomidous M, Kinnunen J, Kózka M, Lesaffre E, McHugh M, MorenoCasbas M.T, Rafferty A, Schwendimann R, Tishelman C, Achterberg T, Sermeus W. RN4CAST consortium. Nurse staffing and education and hospital mortality in nine European countries: a retrospective observational study. Lancet 2014; 24; 383(9931): 1824-1830.

30. Cisek M, Przewoźniak L, Kózka M, Brzostek T, Brzyski P, Ogarek M, Gabryś T, Gajda K, Ksykiewicz-Dorota A. Workload During the Last
Duty in the Opinions of Nurses Working in Hospitals Covered Involved in the RN4CAST Project. Zdr Publ Zarz 2013; 11(2): 210-224.

31. Goncalves LA, Padilha KG. Fatores associados a carga de trabalho de enfermagem em Unidade de Terapia Intensiva. Rev Esc Enferm USP 2007; 41(1): 645-652.

32. Szmurło D, Kostrzewska K, Wojtarowicz M, Widawska A, Kordecka A, Plisko R, Łanda K. Employment Standards of Nurses and Midwives in Hospital Wards - Proposal of Regulation in Poland. Version 1.0. Central and Eastern European Society of Technology Assessment in Health Care (CEESTAHC). Kraków 2013.

33. Stone PW, Pogorzelska M, Kunches L, Hirschhorn LR. Hospital staffing and health care-associated infections: a systematic review of the literaturę. Clin Infect Dis 2008; 47(7): 937-944.

34. Safdar N, Kluger DM, Maki DG. A review of risk factors for catheterrelated bloodstream infection caused by percutaneously inserted, noncuffed central venous catheters: Implications for preventive strategies. Medicine Baltimore 2002; 81(16): 466-479.

35. Trinkoff AM, Johantgen M, Storr CL, Gurses AP, Liang Y, Han K. Linking nursing work environment and patient outcomes. J Nurs Regul 2011; 2: 10-16.

36. Choi SP, Pang SM, Cheung K, Wong TK. Stabilizing and destabilizing forces in the nursing work environment: a qualitative study on turnover intention. Int J Nurs Stud 2011; 48(10): 1290-1301.

37. Griffiths P, Renz A, Hughes J, Rafferty AM. Impact of organisation and management factors on infection control in hospitals: a scoping view. J Hosp Infect 2009; 73(1): 1-14

38. Hugonnet S, Chevrolet JC, Pittet D. The effect of workload on infection risk in critically ill patients. Crit Care Med 2007; 35(1): 76-81.

39. Needleman J, Buerhaus P, Mattke S, Stewart M, Zelevinsky K. Nursestaffing levels and the quality of care in hospitals. N Engl J Med 2002; 346(22): 1715-1722.

40. Fridkin SK, Pear SM, Williamson TH, Galgiani JN, Jarvis WR. The role of understaffing in central venous catheter-associated bloodstream infections. Infect Control Hosp Epidemiol 1996; 17(3): 150-158.

41. Alonso-Echanove J, Edwards JR, Richards MJ, Brennan P, Venezia RA, Keen J, Ashline V, Kirkland K, Chou E, Hupert M, Veeder AV, Speas J, Kaye J, Sharma K, Martin A, Moroz VD, Gaynes RP. Effect of nurse staffing and antimicrobial-impregnated central venous catheters on the risk for bloodstream infections in intensive care units. Infect Control Hosp Epidemiol 2003; 24(12): 916-925.

42. Pronovost PJ, Berenholtz SM, Goeschel C, Thom I, Watson SR, Holzmueller CG, Lyon JS, Lubomski LH, Thompson DA, Needham D, Hyzy R, Welsh R, Roth G, Bander J, Morlock L, Sexton JB. Improving patient safety in intensive care units in Michigan. J Crit Care 2008; 23(2): 207-221. 